\title{
EL ESCRITORIO Y EL MOBILIARIO EN LA VIDA COTIDIANA LIMEÑA A FINES DEL SIGLO XVII
}

\author{
FALL FRONT CABINET AND FURNITURE IN LIMA DAILY LIFE \\ AT THE END OF THE XVII CENTURY
}

Juan Diego Carrillo Thorne*

Universidad Peruana de Ciencias Aplicadas

\section{Resumen}

Dentro del mobiliario, que llegó de España desde la fundación de la ciudad de los Reyes en 1535, el escritorio es parte de la vida cotidiana; este mueble se adapta a los gustos del nuevo poblador limeño, y tiene una serie de manifestaciones en el virreinato que se ven reflejadas en su estética y material. Cumple un papel importante y diverso dentro de los distintos espacios de las casas de morada limeñas; y está muy presente su uso en la vida cotidiana. A fines de siglo XVII, ya encontramos expresiones de dichos muebles en las distintas ciudades del virreinato y especialmente en la capital del virreinato del Perú.

Palabras clave: Investigación Histórica, Mueble, Artes Decorativas, Siglo XVII, Perú.

\section{Abstract}

Within the furniture, which came from Spain since the founding of the City of Kings in 1535, the fall-front cabinet is part of everyday life; this piece of furniture adapts to the taste of the new Lima resident, and has a series of manifestations in the viceroyalty that are reflected in its aesthetics and material. It fulfills an important and diverse role within the different spaces of Lima's dwelling houses; and its use in everyday life is very present. At the end of the $17^{\text {th }}$ century, we already found expressions of said furniture in the different cities of the viceroyalty and especially in the capital of the viceroyalty of Perú.

Keywords: Historical Research, Furniture, Decorative Arts, XVII Century, Perú.

\section{Introducción}

Cuando aparece la vivienda aparece el mobiliario y a través de los siglos éste tiene el poder de modificar los espacios interiores. Los muebles en las diferentes culturas siempre están conectados con el hombre para resolver nuestros problemas de la vida cotidiana. El mueble, dentro de los distintos espacios en las viviendas, es diseñado y construido para facilitar y hacer más cómoda nuestra 
vida diaria. Para ello se toman en el momento de su creación, las referencias culturales, estéticas, funcionales y tecnológicas. Posteriormente a través de los siglos, estos muebles pierden su función original y pasan a ser decorativos, debido a los cambios de la vida diaria y al descubrimiento de nuevos materiales y tecnologías que permiten nuevas soluciones.

Además de sus características físicas el mueble evoca familia, sentimientos, recuerdos y todo aquello ligado a nuestros antepasados. La vida cotidiana a través de los diferentes espacios de una casa de morada limeña de fines del siglo XVII nos permite ubicar su mobiliario, lo cual nos ayuda a entender su uso en la vida diaria y su distribución en una casa de morada. Dentro de este mobiliario, está el escritorio, que hoy en día es un mueble representativo de fines del siglo XVII del virreinato del Perú.

\section{Vida cotidiana en la ciudad de los Reyes a fines del siglo XVII}

La vida cotidiana nos ayuda entender al individuo en distintos contextos, culturas y periodos históricos. Lima es una nueva ciudad fundada en 1535. Ya a fines del siglo XVII está amurallada y encontramos una población que se ha adaptado a un nuevo territorio, con todo lo que este le ofrece: nuevos alimentos, un clima muy templado y una ciudad que se está formando a base de un plano ideal en forma de cuadrícula. Es la capital del virreinato del Perú, donde vive el virrey y las principales autoridades. Es una ciudad que mira hacia España con una población de 37,000 habitantes, aproximadamente unas cinco mil quinientas familias, según el censo de Lima de $1700^{1}$, con una escasa población de trescientos indios que viven en el cercado de los indios, en una zona aislada dentro de la misma ciudad.

La familia limeña está conformada por los padres con dos o tres hijos como promedio, siempre con esclavos negros que son considerados como objetos transables. Esta familia en su mayoría es criolla, española o conformada por un migrante español casado con una mujer limeña. Esta nueva sociedad, basada en la sociedad española de los Habsburgo, se está construyendo en lo político, religioso, social, económico y en lo cotidiano; adaptando en su día a día las costumbres traídas desde España, modificándolas para satisfacer sus necesidades en educación, vestido, alimentación y mobiliario en una nueva ciudad, muy lejana y con características muy distintas de donde vienen.

Tamara Garcia Cuiñas en su artículo Escritorio peruano virreinal en el Museo de América nos describe que:

"El descubrimiento de estos nuevos territorios abrió un nuevo mundo en relación con las materias primas y las técnicas artísticas. El resultado de todo esto fue el enriquecimiento de mobiliario debido al intercambio cultural que se estaba produciendo en estos momentos"2.

En la ciudad de Lima las viviendas, la iglesia y el comercio están muy presentes y entrelazados. La religiosidad está totalmente arraigada en la vida diaria del ciudadano, siendo aproximadamente el $15 \%$ de su población monjas o curas y, con una santa criolla limeña Santa Rosa, canonizada en 1671 por el 
papa Clemente X, muy presente dentro de la sociedad limeña, tanto es así que figuran pinturas de ella en casi todo los inventarios de bienes de la época.

Los artesanos tienen sus talleres por toda la ciudad y, en lo que respecta al trabajo con la madera, encontramos en la descripción que hace Salinas y Cordova ${ }^{3}$ :

"Ensambladores mayores, y Arquitectos, que hazen retablos, doze maestros primos. Ensambladores menores, y ebanistas, muchos maestros, y oficiales, que labran escritorios, y contadores.

Carpinteros mas de trecientos de lo blanco, y Carpinteros de lo negro que hazen carretas, y rodeznos de molinos se hallan ocho tiendas. Carrozeros dos tiendas. Pintores diez tiendas. Doradores doze tiendas. Albañiles mas de trescientos. Torneros seys tiendas. Guarreros, y maestros de instrumentos músicos, cinco tiendas. Doradores doze tiendas... Curtidores seis. Zurradores ${ }^{4}$ quatro, y un Guadamecilero"5.

Podemos apreciar que en la ciudad ya tenemos distintos oficios para los procesos ligados al trabajo de la madera en sus diferentes versiones, entre ellos están los carpinteros, de lo blanco y negro, carroceros, doradores, torneros y curtidores entre otros.

A fines del siglo XVII, en la ciudad se construyen conventos, monasterios e iglesias que se están implementando; y utilizan una mano de obra especializada. A su vez, la vivienda existente, tiene que amoblarse con un mobiliario que llega a Lima a través de la migración, del comercio con oriente, de otras ciudades del virreinato, o es confeccionado por ensambladores menores y ebanistas que residen en la ciudad.

\section{Los ambientes en una casa de morada limeña}

En la ciudad de los Reyes a fines del siglo XVII, las propiedades estaban conformadas por varias casas; la casa principal que es la más importante, donde vive el dueño de la propiedad con su familia se denomina casa de morada, y las que se alquilan simplemente casa. ${ }^{6}$ Cada casa de morada o casa tiene un ingreso a la vivienda, un segundo ingreso a la carrocera y un tercero a una asesoría o tienda donde se ubican los talleres de los diversos artesanos.

Según los estudios presentados por Antonio de San Cristóbal en su libro La casa virreinal limeña de 1570 a 1687, describe hasta ocho tipos de casas; casa de altos y bajos; y casas de bajos, pero todas ellas siempre con componentes comunes. $^{7}$

En este sentido en el inventario de bienes de Doña Antonia Lugones que deja sus bienes al licenciado Don Joseph Navarro Montesinos, Racionero de esta santa iglesia Catedral, dice lo siguiente:

"Primeramente las cassas principales altás y Vajas que fueron de la bivienda y morada de dicha difunta que están en esta Ciudad en la calle que Vaja de la plazuela del santo oficio ${ }^{8}$ a la plaza mayor de esta Ciudad en la primera quadra a mano izquierda que hacen esquina y vuelven 
para la calle que ba a la conpania de Jesus que por todo Son trese puertas a la calle las dos de dos cassas las once Restantes de las casitas y tiendas y carrosera asessorias a ellas ..."9.

En la descripción se indica que son trece puertas, por lo tanto es una propiedad de un área importante, de los cuales dos puertas son, para el ingreso a la casa de morada y carrocera. Al tener dos casas grandes más como se indica, ambas tienen una puerta de ingreso y una carrocera, en total hacen seis puertas. Las siete puertas restantes son para las casas pequeñas y tiendas o asesorías. Esto nos da una idea que en una propiedad habían varios casas de diferentes dimensiones y que siempre están presentes las tiendas o asesorías.

"Las casas limeñas virreinales siguieron un patrón uniforme en cuanto al conjunto de los aposentos componentes, que fueron los mismos específicamente para todos los modelos de casas de vivienda; y fueron asumidos a razón de uno solo de cada clase taxativamente por las viviendas de todos los modelos... Aun en las casas del modelo más complejo, solo describen los conciertos de obra una sala, una cámara con su recamara y una cuadra de estrado" 10 .

Como lo indica Antonio San Cristóbal, en los inventarios de bienes se describe una sala, la cuadra (quadra), la recamara y la cámara o aposento de dormir. La recamara es muy poco mencionada y en los casos que se mencionan hijos, no se describen otros aposentos para dormir pero sí se describen más de una cama. Siempre al fondo de la propiedad está la huerta, la caballeriza y la cocina.

Otros espacios que son descritos en algunos inventarios de bienes de las casas de morada de mayor tamaño es el oratorio; un lugar de paz para rezar que se ubica en un ambiente independiente; y en las casas más pequeñas, existe un mueble que se ubica frente a la cama, en el aposento de dormir. En algunas casas de morada encontramos un estudio, equivalente a una biblioteca hoy en día, de personajes que están ligados a la educación.

"En el diario de viaje a España del Cardenal Francesco Barberini escrito por Cassiano del Pozzo, en 1626, describe las casas que visitaban, anotando cuidadosamente las cosas dignas de consideración que observaba. Autentica admiración les causo la casa del príncipe de Esquilache ${ }^{11}$, donde además de los bufets y objetos curiosos procedentes del Perú, donde había sido virrey, y de las bellas alfombras, les llamo la atención el hecho, antes comentado, de que los muros estuviesen sin tapizar, con cuadros de paisajes y bodegones, pero lo demás absolutamente en blanco"12

Esta descripción del libro el Mueble en España Siglo XVI- XVII de María Paz Aguiló coincide y confirma con lo que se lee en los inventarios de bienes, que siempre se describen pinturas ya sea de Flandes o de Lima con diversidad de temas y un mobiliario que en algunos casos son orientales o de diversas ciudades españolas o del virreinato. 
La casa de morada, que es de uno o dos pisos, es el lugar donde viven y desarrollan las familias limeñas su vida diaria, encontramos una serie de espacios como Jean Baudrillard describe "cada mueble, cada habitación, a su vez interioriza su función y se reviste de dignidad simbólica; la casa entera lleva a su término la integración de las relaciones personales en el grupo semicerrado de la familia." 13

A través de la puerta de calle ingresamos a un zaguán y/o patio principal, que al no tener mobiliario alguno, no es nombrado en los inventarios de bienes pero si en los diversos conciertos. De ahí ingresamos a la sala que es un espacio grande para recibir visita. En el inventario de Bienes de Alvaro de Ibarra describen la sala donde tiene cuadros con diversos temas como, Sansón y Dalila, Lucrecia y Tarquino, cuatro fruteros, un espejo y entre otros un cuadro muy grande, que debió haber sido el principal por sus dimensiones, de la ciudad de Sevilla de cuatro a cinco varas de largo y tres de ancho ${ }^{14}$, es el cuadro que domina el espacio. El mobiliario es muy austero; una mesa de caobana con 24 sillas con un bordado de la encomienda de Alcántara ${ }^{15}$. En otros inventarios se mencionan un aparador, mueble donde se guarda la vajilla que está conformada por porcelana china, jarros de barro de chile y algunos elementos de plata.

De la sala se ingresa directamente a dos espacios, la cuadra y a la recamara, separados los ingresos a dichos ambientes con cortinas o puertas. La cuadra es el espacio para la esposa, mujer que desde los trece años está casada con un hombre mayor, donde hace su vida cotidiana y va a pasar su mayor tiempo diariamente. Ahí recibe a sus amigas, y hace sus labores diarias.

Según el Tesoro de la Lengua Castellana, o española, compuesto por el licenciado don Sebastián Cobarruvias Orozco, y publicado en Madrid en 1611, decía: -"Quadra es la pieza en la casa que está más adentro de la sala, y por la forma que tiene de ordinario quadrada se llama quadra"16.

$\mathrm{Al}$ ingresar a la cuadra vemos un estrado con un espaldar de brocado, contra la pared, y tarimas de madera cubiertas por una alfombra que puede ser de seda de la China, Cayrina o de Quito generalmente. Sobre esta alfombra, hay cojines de terciopelo, aproximadamente $90 \mathrm{cms}$ de longitud con bordados muy elaborados y finos de color carmesí, para que las mujeres vestidas con polleras o sayas se sienten frente a frente apoyándose en dichos cojines, que en las almonedas las describen con precios bastantes altos incluso más caros que algunos muebles. Es importante anotar que el uso de la alfombra es para sentarse sobre ella y no para caminar como hoy en día la utilizamos.

Contra las paredes se colocan cuadros con marcos dorados o de ébano, espejos con marcos de ébano, bufetes y bufetillos, sillas con baqueta de Moscovia o Huamanga ${ }^{17}$, escritorios, escaparates, cajas $^{18}$ y algunos baulitos, como se describe en el inventario de bienes de Fernando de Castilla, caballero de la orden de Santiago. Los muebles en la cuadra son finos y es el lugar donde la mujer puede demostrar la riqueza del matrimonio. También hay muebles que se utilizan sobre el estrado, éstos están dimensionados para ser utilizados por mujeres sentadas sobre la alfombra. Entre ellos tenemos mesitas y bufetillos.

El otro ambiente que se ingresa directamente de la sala es la cámara o aposento de dormir, que tiene lienzos en las paredes de motivos religiosos, que son de devociones y de apostolado. Vemos como elemento principal la cuja, que 
se le denomina a la estructura de la cama, y la cama término que implica todos los textiles que visten la cuja y está conformada por las sabanas, colchas, almohadas y colgaduras.

Enfrente a ella se tiene un pequeño estrado con su alfombra sobrepuesta y un pequeño oratorio para poder rezar y adorar a los santos en diversos momentos del día; costumbre que se mantiene hasta hoy en día.

La cámara es un lugar santo donde se conciben los hijos que forman parte de la familia, que es uno de los fines más importantes de la religión católica, es donde van a rezar a diario al inicio y al final del día, donde las figuras religiosas están presentes siempre en la cámara o aposento de dormir.

La cuja es de distintas maderas como cocobola, granadillo, madera amarilla, también bronceada o dorada con una o dos cabeceras. Algunas muy finas de palosanto y; de ébano y marfil.

María Paz Alonso Aguiló en su libro el Mueble en España siglo XVI-XVII, describe que las cujas de granadillo se producen en Sevilla desde el segundo tercio del siglo XVII "Estas camas figuran a menudo en las cartas de dote sevillana"19 y éstas llegan a Lima, también a través de dotes de españoles para contraer matrimonio con limeñas para formar una familia.

La cama está compuesta por distintos tipos de doseles, con dos cortinas por lado colgadas con argollas, algunas terminan en flecos, una gotera en la parte superior y rodapiés en la parte inferior, sábanas de Bretaña, almohadas de Ruan florete y sobrecamas que pueden ser de seda de la china. Algunas tienen un sol del cielo de la cama.

En el inventario de bienes del General Don Francisco de Figueroa se describe:

"Primeramente una Cuja de madera bronzeada mui maltratada y con falta de perillas ${ }^{20}$ y otra piezas bronceadas con tres ropajes usados y traídos el uno de tela de Sevilla con unos encajetos de oro= Otro de Damasco carmessi guarnecido con unos encajitos mestizos $=\mathrm{Y}$ el otro ropaje de Damasco todo mui viejo y servido se tassso la dicha Cuja y tres ropajes como están en un mil y doscientos pessos $1 \mathrm{~V} 200 \mathrm{p}$

Yten otra Cuja de cocobola usada con una cabezera sola se tasso en sesenta pesos ---Vo60p

Yten dos Catres viejos de Guayaquil en ocho pesos ----Voo8p"21.

Se describen en los bienes del General Figueroa una cuja y cama bastante fina, con telas ricamente elaboradas y trabajadas. En el aposento de dormir también encontramos bufetes, escritorios, sillas, escaparates, cajas y baúles.

Esto implica que en cada espacio encontramos diversos muebles como escaparates, aparadores, bufetes, escritorios, cajas, baúles y sillas entre otros. Todos estos muebles tienen una estética, un lugar y un uso predeterminado en cada habitación. 


\section{Escritorio, un mueble representativo en el siglo XVII}

Los escritorios a fines del siglo XVII, dentro de las casas limeñas, se ubican en la Cuadra, espacio de la mujer, y en la Cámara o aposento de dormir generalmente; y excepcionalmente en la Sala. Es un mueble representativo de la vida cotidiana en el virreinato del Perú y tuvo múltiples usos. En la revisión de las Almonedas e Inventarios de bienes de fines del siglo XVII en el Archivo General de la Nación en Lima, el término utilizado para describirlo es escritorio, en muy pocos casos se le denomina papelera y en ningún documento he encontrado el nombre de arquilla. Como lo indica Maria Paz Aguiló se modificó su nombre por bargueño a fines del siglo XIX, siendo recuperado el término original como figura en los documentos del siglo XVII, por los historiadores a fines del siglo XX.

Debido al desarrollo de nuevas tecnologías y cambios en la vida cotidiana, ha pasado a ser un mueble decorativo perdiendo sus funciones para la cual fue creado. Estos muebles son de diferentes dimensiones, materiales y procedencias; por los sismos, su movilidad y belleza a través de generaciones se han ido perdiendo o saliendo del país, actualmente quedan muy pocos en la ciudad de Lima.

Hay varias formas por el cual llega el mobiliario a la ciudad de los Reyes, Lima: a través de las autoridades españolas o migrantes que vienen desde España, del Virreinato de Nueva España, México, por ejemplo en el inventario de bienes de Doña Gerónima Gomes Pradeda nos describen

“dos escritorios de Sevilla quebrados de madera y huessos... dos dichos de mejico con sus dos contadores hechura ordinaria" 22 , también de Salamanca "un escritorio salamanquino dorado en VO30p"23.

Debido al comercio con Oriente llegaran de la China; "Un escritorio de la china embutido de concha de nacar $=\mathrm{Y}$ dos escribanías embutidas de lo mesmo todo en doscientos pessos---V200p"24 . También, "Un escritorio de la china con su mesa------." “25.

La característica de los escritorios de la China es que están confeccionados con concha de perla; material que no se encuentra en el virreinato del Perú.

En Quito ,capital del Ecuador, que perteneció al virreinato del Perú se produjeron escritorios y los describen de la siguiente forma "Dos escritorios ordinarios de quito" 26 . También "Tres escritorios de quito de bara menos sesma de medio ancho muy viejos y quebrados--." 27.

En el inventario de Doña Sebastiana Medina y Vega viuda del General Antonio Santillana y Hoyos, que vivieron en Quito vemos: "un escritorio grande con su serradura aforrado en badana negra que parece de quito vacio - " 28 .

En la memoria de bienes de Doña Maria Garcia de la Estrella lleva a poder del Doctor Don Marcelo de España se describe escritorios confeccionados con carey y marfil en Quito como se lee "ytten tres escritorios pequeños de carey y marfil hechos en quito a veinte pessos cada uno hacen sesenta pessos-------O060p-“29. 
En las relaciones de mobiliario descritas en los inventarios, nos indican que en Quito existe una producción de escritorios con características propias. Los artesanos producen varios tipos de escritorios en Quito según la moda de la época, como los descritos en madera ordinarias, siendo estos muy sencillos, otros forrados con badana, en este caso negra, y los más finos con carey y marfil materiales que fueron importados ya que no existen en dicha zona.

En la sierra del Perú, también se confeccionan escritorios y los encontramos en Jauja: "dos escritorios de jauja con sus mesas" 30 y "Un escritorio pequeño de jauja en Diez pesos 0010p" 31 Como podemos apreciar existen escritorios de diferentes ciudades con características propias de cada ciudad donde se producen. Esto nos da una idea muy clara que ya, en algunas ciudades del Virreinato del Perú a fines del siglo XVII hay un mobiliario que se ha adaptado a una estética local.

El escritorio es un mueble compuesto por varios cajones pequeños, simétricos, que en algunos casos tienen tapa para cerrarlo, en otros está conformado por gavetas, que son cajones sin frente. Sirve para guardar objetos pequeños como abanicos, molinillos para chocolate, tabaqueros de mate, papeles, joyas entre otros ${ }^{32}$. Siempre va apoyado sobre un bufete o mesa y en algunos casos son una unidad estética.

"La construcción de esos escritorios se va complicando con compartimentos secretos, dobles fondos y cajones aparentes o semiocultos, que determinarán una de sus funciones como contenedores de colecciones en las cámaras de maravillas europeas desde mediados del siglo xvi”33.

En el inventario de Francisca de Vega y Monsalbe, que fue esposa del Maestre de Campo Don Joseph de Castro Ysazaga alcalde ordinario de Lima, se describe:

"Ytem Dos escriptorios De Carey Y marfil Bronceados de bara y media de alto y de lo mismo de ancho con sus Bufetillos y El uno con una lamina En lo alto, de nuestro Señor En el templo Enseñando a los Doctores= y en medio San Juan Ebangelista y abajo el desposorio de nuestra Señora= Y El Otro una lamina En lo alto de la enCarnazion y en El medio San Marcos y mas abajo La visitazion de santa Ysabel= y los escriptorios con sus fundas de Bramante listado.

Ytem otro escriptorio mediano de Marfil de media bara de alto y una de largo. Con otro escritorito arriba de lo mismo con quatro gavetas --.---.-Ytem un escriptorio de Evano y marfil pequeño de tres quartas de ancho y lo mismo de largo Y se abrió y no se hallo en el Cossa de valor ----.--.34”.

Los dos primeros escritorios descritos con más detalle, en el inventario de Francisca de Vega y Monsalbe, nos indican que son escritorios imponentes con un frente cuadrado de $1.20 \mathrm{mts}$ por lado, con motivos religiosos distintos cada uno. Cada escritorio hace un juego con su propio bufetillo y estos en conjunto deben haber llegado a una altura aproximadamente de dos metros como mínimo. 
"La moda de los grandes escritorios de ébano, palosanto y concha con sus bronces dorados de molido se alarga hasta finales del siglo xvii, alcanzando altos precios según consta en la documentación de la época e incluso adentrándose en el siglo XVIII" 35 .

También describe un segundo escritorio más pequeño pero que ambos escritorios están uno encima del otro, y el más alto tiene 4 gavetas que son cajones sin frente; esta es otra forma de que se colocaban estos muebles.

El tercero más pequeño de ébano y marfil también con un frente cuadrado con las mismas dimensiones de largo y alto de tres cuartos (aprox. 0.60cms).

En la memoria de bienes de Doña María Gracia de la Piedra cuñada del doctor Don Marcelo de España encontramos:

"Yten dos escritorios yguales de carey con sus sobrepuestos de bronce dorados con sus mesas en doscientos pesosO200p

Yten otro dicho de evano marfil y Carey grande con su escrivania de lo mismo en doscientos pe O200p-"36.

Otra característica de los escritorios, es que tienen remates de bronce, hay algunos que son por pares iguales o que hacen juego con sus mesas o bufetes; algunos tienen una escribanía ${ }^{37}$ como parte del escritorio.

En el testamento del General de campo Francisco Balverde y Contreras caballero de la orden de Santiago casado con Josepha de Ayala y Alarcón describe "un escritorio de plata sinselada con quatro gavetas que peso sesenta y nueve marcos y quatro onssas ${ }^{38}$ listado" 39

En la dote del capitán Alonso Jiménez Vela de Lara a Josepha Jarana de Mena se lleva "un espejo y un escritorio anbos de plata en dosientos y sinquenta pesos-250p" 40

El virreinato del Perú como productor de plata y con artesanos que la trabajaron muy hábilmente es muy probable que estos escritorios de plata hayan podido confeccionarse en el Perú: El primero por el peso de 15,70041 gramos aproximadamente debió ser íntegramente de plata. Maria paz Aguiló en su libro el Mueble en España siglos XVI-XVII, indica que en España ya en el siglo XVI en el reinado de Felipe II, se hacían escritorios de plata y en el reinado de Felipe IV en 1643 hace fundir toda la plata del Buen Retiro por la banca rota de la corona. Parece debido a la abundancia de la plata esa moda se replicó en el siglo XVII en el virreinato del Perú.

También los hay de madera con cajones pintados y dorados, forrados en baqueta negra y en badana colorada, acabado común entre los escritorios descritos en los inventarios de bienes como: "Un escritorio aforrado en badana colorada con catorsse gavetas" ${ }^{42}$.

"Yten dos escritorios pequeños hordinarios aforrados el uno en badana colorada y el otro en negra viejos de quarta de alto y media de largo" 43 "yten otro escritorio de madera pintados los cajones y dorados viejo a forrado en baqueta negra" 44 
En el inventario de bienes de Doña Josepha de Salazar y del Sol deja“un escritorio de madera de cocobola con la delantera de sobrepuestos de carey dos pares de ygitas de coral la unas con sus aritos y las otras con broqueles ya quebrados" ${ }^{45}$ el cocobola es una madera que se trabaja para hacer muebles como camas y que los carpinteros de Lima la utilizan. Es el único escritorio, que he encontrado con estas características.

En el inventario de bienes del contador mayor Don Joseph Villela y Esquibel describe, "quatro escritorios los dos enbutidos de carey y marfil y los otros dos de nogal enbutidos en naranjo con sus mesas de lo mesmo---“" ${ }^{6}$; nos describe otro tipo de escritorio que hace juego con sus mesas que es el de nogal y embutido en naranjo.

En cuanto a los precios son muy variables, encontramos de Quito en 20 pesos; en Salamanca de 30 pesos. Deben ser escritorios pequeños y sencillos en su confección. Pero también tenemos de mucho más valor; "Yten dos escriptorios de Carey y marfil Con sus mesitas a quatrocientos pessos Cada uno ochocientos pessos --.-V8oop" ${ }^{47}$. Estos escritorios deben ser de una muy buena calidad.

\section{A modo de conclusiones}

Lima a fines del siglo XVII es una ciudad que ya tiene vida propia y permanentemente recibe influencia foránea debido a una migración constante. Es una ciudad donde la vivienda, el comercio e Iglesia está muy interrelacionada. Los ambientes son comunes en las distintas casas de moradas y casas, independiente de las dimensiones de estas; estos son: sala, cuadra, cámara y recámara, patio, huerto y cocina. Donde encontramos los escritorios es en la cuadra y el dormitorio y excepcionalmente en la sala.

La cuadra es el espacio de la mujer donde recibe a sus amigas sobre un estrado con alfombra, en la cual se sientan y se apoyan sobre unos cojines, hace su vida cotidiana y tiene un mobiliario que se adapta a sus necesidades y refleja su nivel económico.

El dormitorio es un lugar santo donde se reza diariamente y se concibe a los hijos bajo el amor de Dios; estos estarán protegidos por los santos y el señor que están presentes en los diversos lienzos colgados en las paredes.

El escritorio es un mueble que está ubicado en la cuadra y aposento de dormir, que siempre va sobre un bufete, y sirve para guardar objetos pequeños. Su característica es de estar conformado por cajones y o gavetas dependiendo su uso.

La procedencia de los escritorios encontrados en los inventarios de bienes fines del siglo XVII son de España, China, México, y dentro del virreinato del Perú en Quito y Jauja ${ }^{48}$. Las maderas con las que están confeccionados son cocobola, granadillo y los más finos de ébano, marfil y carey. También hay acabados en baqueta negra, badana negra, y dorados. Existieron de diversas dimensiones.

En el virreinato del Perú también se confeccionaron en la ciudad de Quito, escritorios de ébano marfil y carey, y de otras maderas. Según lo descrito en los inventarios estos escritorios de Quito tenían unas características que los diferenciaban. También se ha encontrado escritorios de plata, muy probamente confeccionados en el virreinato del Perú. 


\section{NOTAS}

${ }^{1}$ Censo hecho en la ciudad de Lima, durante el gobierno del virrey Melchor Portocarrero Laso de la Vega, Conde de la Moncloa. Donde se indica claramente la composición familiar y la ubicación de los habitantes por sectores de la ciudad.

${ }^{2}$ Tamara García Cuiñas, "Escritorio peruano virreinal en el museo de América, Un estudio sobre una pieza del siglo XVII,"Res Mobilis. Revista internacional de investigación en mobiliario y objetos decorativos vol. 5, no 5 (2016): 211 .

${ }^{3}$ Buenaventura Salinas y Cordova, Memorial de las Historias del Nuevo Mundo Perú (Biblioteca Digital Hispana, 2020), 251.

${ }^{4}$ Es la segunda fase de curtido.

${ }^{5}$ Son los que doran o platean el cuero

${ }^{6}$ La denominación de casa de morada y casa figura en los inventarios de bienes y en los alquileres de los protocolos de fines del siglo XVII.

${ }^{7}$ Los elementos comunes de las viviendas lo integran la sala, cámara de dormir, y la recamara adjunta, la cocina, la despensa y el patio. También señala la cuadra de estrado y el zaguán. p.455.

${ }^{8}$ La plazuela del santo oficio de la inquisición es la plaza donde se encontraba el tribunal de la santa inquisición.

${ }^{9}$ Archivo General de la Nación (AGN), 1690. Figueroa Dávila Joseph. Protocolo 575, f 1R a 6R.

${ }^{10}$ Antonio San Cristóbal, La casa virreinal limeña de 1570 a 1687, Tomo II (Lima: Fondo editorial del Congreso del Perú, 2003), 465-466

${ }^{11}$ Francisco de Borja y Aragón, Príncipe de Esquilache, Virrey del Perú 1615-1621

${ }^{12} \mathrm{M}^{\mathrm{a}}$ Paz Aguiló Alonso, El Mueble en España, siglos XVI-XVII (Madrid: Antiquaria, 1993), 18.

${ }^{13}$ Jean Baudrillard, El sistema de los objetos (México, Gallimard, 1969), 13.

${ }^{14}$ En metros $3.75 \times 2.50$ aprox.

${ }^{15}$ Una de las órdenes militares.

${ }^{16}$ Sebastián Covarrubias, Tesoro de la lengua castellana o española, 1611 (Sevilla: Biblioteca Universitaria de Sevilla Fondo Antiguo), 601.

${ }^{17}$ Ciudad ubicada en la sierra del Perú.

${ }^{18}$ Estas cajas son de Panamá por lo general y de diversos tamaños. En ellas se guardan objetos y ropa.

${ }^{19} \mathrm{M}^{\mathrm{a}}$ Paz Aguiló Alonso, El Mueble en España, siglos XVI-XVII (Madrid: Antiquaria, 1993), 149.

${ }^{20}$ Cualquier adorno que se hace en figuras de pera, que ordinariamente se pone en barandillas, camas, bastones.

${ }^{21}$ AGN Perez Cavañas Pedro, 1690b. Protocolo 1426 f 1690R

${ }^{22}$ AGN Sanchez Becerra Francisco, 1692. Protocolo 1707 f 2071V.

${ }^{23}$ AGN Marquez de Guzman Diego, 1696-97. Protocolo 1063 707V.

${ }^{24}$ AGN Perez de Cavañas Pedro, 1690b. Protocolo $1426 \mathrm{f} 1691 \mathrm{~V}$

${ }^{25}$ AGN Nuñez de Porras Juan, 1698 Protocolo 1269 f723R

${ }^{26}$ AGN Quesada Thomas de, 1676 Protocolo 1576 f 897V.

${ }^{27}$ AGN Perez de Soto Francisco, 1688. Protocolo $1530 \mathrm{f}$ 122R a 125R.

${ }^{28}$ AGN Figueroa Marco Antonio de, 1671b. Protocolo $668 \mathrm{f} 2020 \mathrm{R}$.

${ }^{29}$ AGN Taboada Francisco, 1681-1685. Protocolo $1841 \mathrm{f} 2 \mathrm{R}$ y $3 \mathrm{~V}$

${ }^{30}$ AGN Nuñez de Porras Juan, 1698. Protocolo 1269 f 723R.

${ }^{31}$ AGN Perez de Landero Pedro, 1673b. Protocolo 1458 f SFR.

${ }^{32}$ En el inventario de bienes de Sebastiana Medina y Vega viuda de Antonio Santillana y Hoyos describe lo que guarda dentro de un escritorio. En AGN Figueroa Marco Antonio de, 1671b Protocolo 668 f2013V y 2014R.

${ }^{33}$ María Paz Aguiló Alonso,Escritorios y bargueños españoles (Madrid: Ministerio de Economía y Empresa, 2018), 14. 
${ }^{34}$ AGN Fernandez Salcedo Bartolomé, 1676. Protocolo 525 f $204 \mathrm{~V}$.

${ }^{35}$ María Paz Aguiló Alonso,Escritorios y bargueños españoles (Madrid: Ministerio de Economía y Empresa, 2018), 65.

${ }^{36}$ AGN Taboada Francisco, 1681-1685. Protocolo 1841 f 2 R y 3V

${ }^{37}$ Es la caja donde se trae el dinero cobrado, unas son portátiles y otras de asiento.

${ }^{38}$ Es el equivalente a 16 kilos aprox.

${ }^{39}$ AGN Fernandez Salcedo Bartolome, 1673a. Protocolo 519 f $64 R$.

${ }^{40}$ AGN Beltran Juan de, 1689. Protocolo 204 f 39R.

${ }^{41}$ Según Carlos Morales en el libro Historia de la moneda en el Perú un marco de plata equivale a 8 onzas por lo tanto 69 marcos y 4 onzas equivalen a 556 onzas.

${ }^{42}$ Especie de caja corrediza y sin tapa que hay en los escritorios y papeleras y sirve para guardar lo que se quiere tener a la mano.

${ }^{43}$ AGN Figueroa Marco Antonio de, 1671b. Protocolo 668 f $2015 \mathrm{~V}$.

${ }^{44}$ AGN Figueroa Marco Antonio de, 1671b. Protocolo 668 f 2013V.

${ }^{45}$ AGN Nuñez de Porras Juan, 16 Protocolo 1265 f 462V.

${ }^{46}$ AGN Perez de Landero Pedro, 1699a. Protocolo 1519 f $209 \mathrm{R}$ y 209V.

${ }^{47}$ AGN Rivera Matheo de, 1687-1690. Protocolo 1634. F 42V a 45R.

${ }^{48}$ Es un pueblo del Perú. 